\title{
Policy to Localize SDGs as Cultural Agent in Central Java
}

\author{
Amirudin Amirudin ${ }^{1,}$ \\ ${ }^{1}$ Department of Anthropology, Faculty of Humanities, Universitas Diponegoro, Kampus Undip \\ Tembalang, Semarang - 50275, Jawa Tengah, Indonesia
}

\begin{abstract}
This article is derived from research of policy to localize the SDGs as a cultural agent in Central Java. This study aims to reveal how the policies formulated by the actors (state and non-state actors) that act as agents in a way of thinking in region development with the SDGs perspective. This study works with Shore and Wright's (1993) anthropological theory of policy which examines policy as a cultural agent. This study was carried out using ethnographic methods. Data collection was carried out through interviews with 30 informants for 2 months from March 1 to April 30, 2021 at the the Office of Regional Planning and Development Agency (RPDA) of Central Java. The study found that the policy of localizing the SDGs that was realized into the action plan for implementing the SDGs took place as a market metaphor. The actors who are members of the state and non-state actors make the policy as an agent to canalize and debate the cultural discourses that they get through the socialization process in their fields. A number of these multi-directional goals are united in a commitment to position the SDGs as a solution to overcome the real conditions of strategic problems.
\end{abstract}

\section{Introduction}

The Sustainable Development Goals (SDGs) are a global development agenda agreed by 193 countries for the safety of the earth and people until 2030 [1,2]. The international agreement is a commitment for all developed and developing countries to improve economic welfare fairly and sustainably, maintain the quality of the environment and social life, and ensure governance that can maintain the quality of life across generations $[3,4]$.

The Indonesian government places the SDGs as a development priority that requires policy synergy at the national and regional levels, both at the provincial and district/city levels $[5,6]$. Therefore, the target for achieving the SDGs at the national level must be in line with the National Medium-Term Development Plan (RPJMN) 2020-2024, and the target for achieving the SDGs in the regions must be in line with the Regional MediumTerm Development Plan (RPJMD) of each province and district/city.

Efforts to implement the SDGs in the regions are manifold. Each province and district/city has its methods and strategies. Many studies reveal how local governments localize the SDGs as a new development perspective. Research by Edward et al. (2021); Bourlon et al. (2021); Tsiouni (2021), for example, shows that efforts to localize the SDGs 
apply a kind of linear process model that is carried out through the stages of understanding the SDGs, forming institutions, setting goals based on strategic issues in the region, implementing action plans, monitoring and evaluation, communicating, reporting [7,8,9]. This study looks pretty mechanistic that occupy the localization of SDGs as stages in management. In contrast to that research, Kourtzanidis et al. (2021) found that efforts to localize the SDGs tend to proceed like a cultivation model, which is done by integrating the SDGs into regional planning documents [10]. This research seems similar to positioning the localization of the SDGs into the technical aspect of integrating two agendas between SDGs and regional development.

The difference in research is seen in the studying of and Kourtzanidis (2021) and Muerza et al. (2021), which examines the localization of the SDGs from the aspect of language and power exchange, how a policy is formulated on the debate between state and non-state actors in a variety of multi-directional interests $(11,12)$. This research is interesting because it has used an anthropological approach to examine the patterns of language (discourse) exchange and the actors' power in the formulation of the policy. However, this research contains some weaknesses considering that it does not reveal how the SDGs as a new perspective or culture is mediated in the policy. Shore and Wright (1993) call this research a policy as a cultural agent study, investigating how a new idea flows from actor to actor from location to location to form the actual structure that guides the development process in the region [12]. Based on the idea of Shore and Wright, this research was carried out.

Conceptually, Shore and Wright (1993) define a cultural agent as the capacity of the agent as a source of knowledge that guides his actions [12]. In that context, culture is a system of knowledge, and an agent is seen as an agent's cultural element with the capacity to bring about actual action. The concept of the agent is not only an explanation of how an effort may be carried out by humans but also serves to explain the dynamics of the relations between individuals or agents and social structures [13]. Especially regarding relationships between individual and social structures, the concept of the agent is used to explain the ability of individual consciousness to organize their awareness and explain the capacity of individuals to act independently and free from structural determination [13].

As an anthropological topic, the agent concept describes the main problem in social science theory, namely the autonomy of individual acts [12]. On the one hand, there is a view of culturalism that tends to minimize the role of individual freedom and places it only as a body that passively carries out the rules of the cultural structure [13]. On the other hand, an ethnomethodological view sees social structure as a problem that can be solved and formed by individuals, and therefore, has no determination over the individual [13]. There have been many attempts by anthropologists to reconcile the tensions of these approaches, but a balanced compromise is hard to come, and in the end, some anthropologists accentuate one or the other.

\section{Methods}

This research was conducted in the Central Java Provincial Government, implementing the SDGs through the ethnographic method. Since 2017, the government has implemented the SDGs by forming a Regional Coordination Team (RCT) for the Sustainable Development Goals, mainstreaming the SDGs into regional planning documents, integrating them and compiling a Regional Action Plan (RAP) for the Implementation of the Sustainable Development Goals. The policy to localize the SDGs has been carried out by the Office of Regional Planning and Development Agency (RPDA) as the leading sector. It appears that efforts to localize the SDGs are not only carried out at the level of translation (operationalization) of goals, targets, and indicators into regional planning documents but 
also at integrating new perspectives into the development process in the regions. To examine the extent to which the localizing SDGs policy is positioned as a cultural agent, observations and interviews have been conducted with 30 informants consisting of state actors such as the Head of RPDA Office, Head of the Regional Coordination Team, Head of the Provincial SDGs Secretariat, Head of Regional Government Organizations (RGP), Head of Central Bureau of Statistics (CBS), as well as elements of Non-State Actor. Data collection was carried out for two months starting March 1 - April 30, 2021. This method was intended to reveal a portrait of the perspective of 30 informants in formulating policies.

\section{Result \& Discussion}

\subsection{SDGs Localization Policy in Central Java}

Based on Based on close observations and in-depth interviews with informants about the existing conditions of SDGs implementation in Central Java, this research found that since the global agenda was set as the national development through Presidential Decree No. 59 of 2017, the Central Java Provincial Government began to respond to implement it by understanding the SDGs. According to Fertilia (41 years old), a functional planning officer involved in implementing the Millennium Development Goals (MDGs) since the implementation, it started by recruiting four contract workers consisting of 1 SDGs expert and two analysts, and 1 data collector. These four contract workers are reserved as supporting staff when the SDGs Secretariat is formed at the Office of the Regional Development Planning Agency (RDPA) of Central Java. By the Head of RDPA, the SDGs Secretariat was formed in January 2018 with the main task of initiating the institutional formation of the Regional Coordination Team (RCT) for the Implementation of Sustainable Development Goals, mapping and tagging analysis of the Regional Medium Term Development Plan (RMTDP) document for the integration of SDGs into the action plan document.

The SDGs secretariat team led by echelon-3 officials (Secretary of the RDAP Office) started work by first internalizing the SDGs within the internal environment of the provincial and district/city governments. In the next step, he initiated the formation of the Regional Coordination Team (RCT) to implement the SDGs. In that context, informant Indiarto (53 years old) explained that the formation of RCT began with several meetings with State Actors consisting of RGP in the Provincial Government and district/city governments) ; and also Non-State Actor.

They hold the principle of inclusion, and no one is left behind as a guide in the formation of RCT institutions. Any candidates from various institutions were invited to the perception equalization forum. After achieving a common understanding among the actors, the SDGs Secretariat Team then facilitated the formation of RCT institution, which the Head of RDPA Office chaired. RCT membership is very large, reaching 160 people. All of this is intended so that the RCT institution accommodates as many actors as possible as the embodiment of the principle of inclusion and no one left behind.

Edy Wahyono (54 years old), Head of Government and Socio-Cultural Affairs, explained that the RCT institution was formed to coordinate activities to localize SDGs by preparing the SDGs Regional Action Plan (RAP). Facilitated by the SDGs Secretariat, RCT prepares RAP through a number of stages, including scheduling plenary meetings, setting goals and indicators, formulating targets, policy directions and work programs, and preparing the mechanism and schedule monitoring and evaluation.

The process of preparing the RAPis carried out in plenary meetings and working groups, including working groups for social pillars, economic pillars, environmental pillars, 
as well as legal and governance pillars. Each working group is given four meetings to prepare a RAP draft according to the posts. After drafting-1, the RCT then held a plenary meeting to establish RAP as an action plan for implementing the SDGs in Central Java.

\subsection{Regional Action Plan (RAP) as a Cultural Agent}

The RAP preparation process is dynamic. The work meetings on the social pillars were exciting. Ika (35 years old), a representative of the Non-State Actor LRC-KJHAM, specifically highlighted cases of violence against children and women, which from time to time increased. They object that the handling of violence against children and women in goal-5 (gender equality) only uses numerical data from the agency that handles it.

The data is biased because there are many cases of violence whose complaints are submitted to the LRC-KJHM, as a Non-State Actor, differently from those submitted to the service. According to LRC-KJHAM, most cases of violence experienced by children and women are sexual violence. Meanwhile, according to the agent, most cases were Domestic Violence). For Ika, data harmonisation is important to determine which goals need to be mitigated and which are only sufficiently strengthened. Likewise, for the placement of goals as a priority, which ones need to be positioned as the most priority and which ones are quite moderate-priority $[14,15]$.

There are many non-state actors like Ika (35 years old) who in the discussion demand that goal handling consider priority aspects and handling strategies. These two aspects are important and connected to how a policy will represent the level of relevance and urgency of the context, real conditions and strategic problems experienced. Based on the interviews with 30 informants, the debates of the actors about the relevance and urgency of the placement of goals and coping strategies are explained in table- 1 below.

Table 1. Agreement on Setting Goals in Localizing SDGs in Central Java.

\begin{tabular}{|l|c|c|c|c|c|}
\hline STRATEGY & \multicolumn{4}{|c|}{ GOALS POSITION } & $\begin{array}{c}\text { AMOUNT } \\
(\%)\end{array}$ \\
\cline { 2 - 5 } & $\begin{array}{c}\text { Moderate } \\
\text { Goals }\end{array}$ & F (\%) & Priority Goals & F (\%) & \\
\hline Mitigation & G16, & $\begin{array}{c}7 \\
(23,33)\end{array}$ & $\begin{array}{c}\text { G1,G2 G3,G4 } \\
\text { G5, }\end{array}$ & $12(40.00 \%)$ & $\begin{array}{c}19 \\
(63.33 \%)\end{array}$ \\
\hline Strengthening & $\begin{array}{c}\text { G6, G11, G12, } \\
\text { G13, G14, } \\
\text { G15, }\end{array}$ & $\begin{array}{c}3 \\
(10,00)\end{array}$ & $\begin{array}{c}\text { G7, G8, G9, } \\
\text { G10, G17 }\end{array}$ & $\begin{array}{c}8 \\
(26.67 \%)\end{array}$ & $\begin{array}{c}11 \\
(36.67 \%)\end{array}$ \\
\hline Informant & & $10(33,33)$ & & $20(66.67 \%)$ & $\begin{array}{c}30 \\
(100 \%)\end{array}$ \\
\hline
\end{tabular}

Source: Analysis of Interview Results

Description: $\mathrm{G}=$ Goals in SDGs, $\mathrm{F}=$ Frequency, $\%=$ Percentage

Based on table-1, it shows that most of the informants position the goals that are incorporated in the social pillars (G1, G2 G3, G4 G5) and the economic pillars (G7, G8, G9, G10, G17) as the most-priority. It can be seen that $40.00 \%$ (social pillar) and $26.67 \%$ (economy pillar) pay attention, respectively. Meanwhile, several goals that are incorporated in the legal and governance pillars (G16) and the environmental pillars (G6, G11, G12, G13, G14, G15) are positioned as moderate-priority, each of which is the concern of $23.33 \%$ (law pillar and governance) and $10.00 \%$ (environmental pillar). Likewise, in terms of handling, it appears that there are two strategies chosen, namely mitigation aimed at goals that have strong relevance to the context, real conditions and strategic problems that are being experienced. It is noted that the goals incorporated in the legal and governance pillars and the social pillars are positioned as goals that need to be addressed through a mitigation approach (63.33\%). Meanwhile, it is sufficient to approach the goals in the 
environmental pillar (10.00\%) and the economic pillar $(26.67 \%)$ with an enhancement strategy only.

This can be seen from the debate; each actor has his perspective on a goal to be handled. This perspective determines the position of each actor in the debate arena. In carrying out their daily tasks, many of them gain experience and knowledge that eventually become part of their culture. These cultural experiences form trajectories as identities that show where they come from. The trajectory acts as a cultural capital for each actor to meet in producing and reproducing policies to move action (Bourdieu, 1993) [13, 15,16].

In drafting the RAP, several debates took place in one field and resulted in an agreement by actors to commit to implementing the SDGs as many as 17 goals, 84 targets, and 251 indicators for 2019-2023. Of these indicators, according to Edy Wahyono, Central Java already has achievement data that can be provided for 192 indicators $(76.49 \%)$ because most of the SDGs indicators have become performance indicators in regional planning documents. Meanwhile, the remaining 59 indicators $(23.51 \%)$ are not yet available. This happens because the 59 SDGs hands have not been played as performance indicators in the regional development plan [17]. A complete description of the number of indicators based on the authority and availability of existing data can be seen in Table 2 below.

Table 2. Number of SDGs indicators based on authority and data availability in Central Java Province.

\begin{tabular}{|l|c|c|c|}
\hline AVAILABILITY OF & \multicolumn{2}{|c|}{ AUTHORITY } & \multirow{2}{*}{ AMOUNT } \\
\cline { 2 - 3 } DATA INDICATORS & REGIONAL & NATIONAL & \\
\hline Indicators of Available & 182 & $10(3,98 \%)$ & 192 \\
Achievement Data & $(72,51 \%)$ & & $(76,49 \%)$ \\
\hline Indicators of Non- & 0 & 59 & 59 \\
Available Achievement & & $(23,51 \%)$ & $(23,51 \%)$ \\
Data & 182 & 69 & 251 \\
\hline Amount & $(72,51 \%)$ & $(27,49 \%)$ & $(100 \%)$ \\
\hline
\end{tabular}

Source: Analysis of Interview Results

Description: (1) Authority refers to indicators that are the authority of the central government and local governments; (2) Data availability is the availability of data that can be provided by the central government and local governments.

Commitment to implementing the SDGs is demonstrated by authority and the availability of data on all SDGs indicators and the budget allocation. At least, with budget allocation data showing real programs implemented by state and non-state actors to fulfil the scenario of implementing goals, it looks more concrete. A complete picture of the commitment of each actor in implementing the SDGs can be seen in the budget allocation data in table 3 below.

Table 3. Budget Support from Government and Non-Government Elements for SDGs in Central Java in 2019-2020.

\begin{tabular}{|l|c|c|c|c|}
\hline PILLAR OF & \multicolumn{2}{|c|}{ GOVERNMENT } & \multicolumn{2}{c|}{ NON-GOVERNMENT } \\
\cline { 2 - 5 } DEVELOPMEN & $\begin{array}{c}\mathbf{2 0 1 9} \\
\text { (Rp 000)/\% }\end{array}$ & $\begin{array}{c}\mathbf{2 0 2 0} \\
\text { (Rp 000)/\% }\end{array}$ & $\begin{array}{c}\mathbf{2 0 1 9} \\
\text { (Rp 000)/\% }\end{array}$ & $\begin{array}{c}\mathbf{2 0 2 0} \\
\text { (Rp 000) } \\
\text { /\% }\end{array}$ \\
\hline \hline Social Pillar (G1, & 812.665 .714 & 1.185 .819 .599 & 18.938 .633 & 2.019 .024 \\
G2, G3, G4, G5) & $(5.14 \%)$ & $(7.89 \%)$ & $(35.93 \%)$ & $(4.67 \%)$ \\
& & & & \\
\hline Economy & 14.625 .976 .357 & 13.345 .311 .008 & 33.755 .495 & 29.795 .038 \\
Pillar(G7, G8, G9, & $(92.53 \%)$ & $(88.85 \%)$ & $(64.04 \%)$ & $(68.90 \%)$ \\
G10, G17) & & & & \\
\hline
\end{tabular}




\begin{tabular}{|c|c|c|c|c|}
\hline $\begin{array}{l}\text { Environmental } \\
\text { Pillar (G6, G11, } \\
\text { G12, G13, G14, } \\
\text { G15) }\end{array}$ & $\begin{array}{c}134.081 .949 \\
(0.84 \%)\end{array}$ & $\begin{array}{c}147.460 .289 \\
(0.98 \%)\end{array}$ & $\begin{array}{l}13.000 \\
(0.02 \%)\end{array}$ & $\begin{array}{l}39.620 \\
(0.09 \%)\end{array}$ \\
\hline $\begin{array}{l}\text { Pillars of Law \& } \\
\text { Governance (G16) }\end{array}$ & $\begin{array}{c}32.541 .239 \\
(0,20 \%)\end{array}$ & $\begin{array}{c}31.124 .594 \\
(0,20 \%)\end{array}$ & 0 & 0 \\
\hline AMOUNT & 15.805 .265 .259 & 15.019 .430 .490 & 52.707 .128 & 43.237 .647 \\
\hline
\end{tabular}

Source: Results of Interview with Informant Edi Wahyono

Description: $\mathrm{G}=$ Goals in SDGs, $\mathrm{F}=$ Frequency, $\%=$ Percentage

Based on table 3 shows, there are various commitments in terms of budget allocation. For 2019 and 2020, it can be seen that the SDGs in the economic pillar appear to be a strong priority. It was recorded that in 2019 the budget allocation contributed $92.53 \%$, and in 2020 it was $88.85 \%$ for the achievement of the SDGs in the economic pillar. Meanwhile, the rest is for the accomplishment of the social pillar SDGs in 2019 by $5.14 \%$ and in 2020 by $7.89 \%$; environmental pillar in 2019 by $0.84 \%$ and in 2020 by $0.98 \%$; and the pillars of law and governance in 2029 by $0.20 \%$ and in 2020 by $0.20 \%$. Likewise, non-state actors in almost the same proportion show the same level of focus. This all happened because nationally, the central government targets an economic growth rate of $7 \%$ for 2020 . As a consequence of such a large target, each region is obliged to direct its budget policies that support the pillars of economic development.

Based on these findings, if the policy to localize the SDGs is positioned as an agent of discourse exchange (Shore and Wright, 1993), it is clear how the policy formulation illustrates the dynamics of the production and reproduction process of policies that occur $[18,19,20]$. A kind of market metaphor takes place in the policy-making process, where it can be seen from the process of exchanging discourses between state and non-state actors in determining what is urgent and not urgent in terms of the context and conditions of real problems faced in the region]. This aspect is at the core of how the choice of goals and approaches to handling and budget allocation is realized to form a pattern of setting goals in an area, as illustrated in table 1 and table 3 above.

\section{Conclusion}

Based on Based on the findings above, it can be concluded that the policy of localizing the SDGs into an action plan for implementing the SDGs in the regions occurs like an association of market metaphor. The actors, both state and non-state actors, use the SDGs localization policy as an agent to canalize and debate the cultural discourses they have acquired through the process of socialization and practical experience in fields themselves. And a number of these multi-directional goals then merge into a shared commitment on how the SDGs are positioned as a way out to overcome the context and real conditions of strategic problems faced in Central Java.

With its sensitivity to capture the actor's point of view and how they argue, combined with its capacity to debate what can be accepted, rejected, and agreed upon, this ethnographic research is well suited for analyzing how these viewpoints infiltrate each other's public policymaking institutions.

In that context, reconfiguring the perspective of actors who are positioning themselves as subjects in policymaking is a starting point for how policy research with a progressive anthropological perspective is important to develop.

This research was carried out with the support of the Dean of the Faculty of Humanities, Universitas Diponegoro, the Head of the Regional Development Planning Agency (Bappeda) of Central Java Province, and 30 informants from state actors and non-state actors. For this reason, the researchers 
would like to thank all of them for the completion of the research and the publication of the results of this research.

\section{References}

1. UN General Assembly. 2015. Transforming our World: the 2030 Agenda for Sustainable Development. NY: UN

2. UN General Assembly. 2012. Resolution Adopted by General Assembly on 27 July 2021: 66/288. The Future We Want. Sizty-sixth Session Agenda Item 19. USA: General Assembly.

3. Allen, Cameron et al. 2018. Initial Progress in Implementing the SDGs: a Review of Evidence from Countries. Sustainability Science. http://doi.org/10.1007/s11625-0180572-3

4. Reyhan, Genly Yigiter, Funda Yirmibesogilu. 2011. Local Agenda 21 and Sustainable Development: The case of Harran. Turkey. Urban Izziv, 2011. Vol. 22 No. 1 (2011). Pp. 144-153

5. Bappenas. 2019. Roadmap of SDGs Indonesia: a Highlight. Jakarta: Ministtry of National Development Planning/National Development Planning Agency.

6. Andre, Maria Helena. 2018. Tujuan Pembangunan Milllenium: Referensi Manual Serikat Pekerja pada Agenda untuk Pembangunan Berkelanjutan 2030. Jakarta: Organisasi Perburuhan Internasional (ILO). ISBN 97-92-2830927-0

7. Edward, J. Riley et al. 2021. A Roadmap for Sustainable Smart Track-Wireless Continuous Monitoring of Railway Track Condition. Sustainability 2021, 13, 7456. https://doi.org/10.3390/su13137456

8. Bourlon, Fabien, et al. 2021. Grounding Sustainable Tourism in Science-A Geographic Approach. Sustainability 2021, 13, 7455. https://doi.org/10.3390/su13137455

9. Tsiouni, Maria. 2021. Economic and Financial Sustainability Dependency on Subsidies: The Case of Goat Farms in Greece. Sustainability 2021, 13, 7441. https://doi.org/10.3390/su13137441

10. Kourtzanidis, Konstantinos, et al. 2021. Assessing Impact, Performance and Sustainability Potential

11. Kourtzanidis, K. 2021. Smart City Projects: Towards a Case Agnostic Evaluation Framework. Sustainability 2021, 13, 7395. https://doi.org/10.3390/su13137395

12. Muerza, Victoria et al. 2021. Sustainable Construction Logistics in Urban Areas: A Framework for Assessing the Suitability of the Implementation of Construction $\begin{array}{lllll}\text { Consolidation } \quad \text { Centres. } & \text { Sustainability }\end{array}$ https://doi.org/10.3390/su13137349

13. Shore, Cris and Susan Wright. 1997. Anthropology of Policy : Critical Perspective on Governance and Power. London and New York : Roudledge

14. Bourdieu, Pierre. 1993. The Field of Cultural Production: Essays on Art and Literature. New York : Columbia University.

15. Yusliza, Mohd Yusoff, et al. 2020. An Investigation of Pro-Environmental Behaviour and Sustainable Development in Malaysia. Sustainability 2020, 12, 7083; doi:10.3390/su12177083

16. Toolis, Erin E. 2021. Restoring the Balance between People, Places, and Profits: A Psychosocial Analysis of Uneven Community Development and the Case for 
$\begin{array}{lllll}\text { Placemaking } \quad \text { Processes. } & \text { Sustainability }\end{array}$ https://doi.org/10.3390/su13137256

17. Cerisola, Silvia; Elisa Panzera. 2021. Cultural and Creative Cities and Regional Economic Efficiency: Context Conditions as Catalyzers of Cultural Vibrancy and Creative Economy. Sustainability 2021, 13, 7150. https://doi.org/10.3390/su13137150

18. Amirudin, Amirudin, et al. 2021. The Impact of the COVID-19 Self-Isolation Policy on the Occupations of Vulnerable Groups Int. J. Environ. Res. Public Health 2021, 18, 6452. https://doi.org/10.3390/ijerph18126452

19. Amirudin, Amirudin. 2019. Environmental Issues in Journalism Coverage at the Suara Merdeka Newspaper E3S W eb of Conferences 125, 0 (2019) https://doi.org/10.1051/e3sconf/20191250 ICENIS 201920192019

20. A Spinelli, G-Pellino.2020. COVID- 19 Pandemic: Perspectives on an Unfolding Crisis. British Journal Surgery, (2020), DOI : 10.1002/bjs.11627 